\title{
Adherence and Pharmaco-Care Interventions Amidst HIV Patients ON COMBINED ANTIRETRoviral THERAPY IN NIGERIA
}

\author{
Shakirat Iyabo Bello* \\ Department of Clinical Pharmacy and Pharmacy Practice, Faculty of Pharmaceutical Sciences, \\ University of Ilorin, Ilorin 240003, Kwara State, Nigeria \\ *E-mail: sibello10@yahoo.com \\ Tel.: +2348035675609.
}

Received: May 14, 2017 / Revised: Jul 21, 2017 / Accepted: Jul 22, 2017

\begin{abstract}
Present study examines the level of adherence and pharmaceutical care interventions among HIV patients on combined antiretroviral therapy in Nigeria. Adherence to cART among 297 patients was determined using pill counting method. The levels of patient adherence were evaluated at baseline and then re-evaluated at three, six, and nine months. The subjects were also followed up with drug counseling at 3 months interval of the hospital visit for prescription refills. More than one-half of them were on CART between 2 and 3 years. At baseline, the adherence level obtained from pill counting was $85.9 \%$. Following the patient-focused interventions, the adherence level steadily increased to $\mathbf{9 7 \%}$. Before the intervention, patients most adhered to Tenofovir + Emtricitabine + Efavirenz followed by Zidovudine + Lamivudine + Efavirenz. After the intervention, there was an improvement in adherence level to all the regimens of drugs used for the patients. In treating HIVinfected subjects on combined antiretroviral therapy, application of pharmaceutical interventions and continual monitoring are essential to heighten adherence and promote survival.
\end{abstract}

Key words: Pharmaceutical care, Adherence, Line regimen, Pill counting, Antiretroviral therapy.

\section{INTRODUCTION}

Some HIV-infected patients do not gain from combined Antiretroviral Therapy (cART) due to non-adherence and this poses long-term threat for the efficacy of cART (Adefolalu and Nkosi, 2013). The success of cART depends on sustainable superior levels of adherence (National Consolidated Guidelines, 2015). Whether the patient is treatment inexperienced or treatment experienced, the chance of adherent diminishes over time (Hornschuh et al 2017). Pill count method of adherence however, involves physical counting of patient remaining pills by the pharmacist, nurse, physician or other health-care practitioners. There are beneficial effects of adherence to therapy in HIV-infected patients. There is a virologic failure among non- adherent patients when compared to adequately adherent patients. The increase in adherence leads to increase in $\mathrm{CD}_{4}$ count. Non-adherence correlated with a longer stay on hospital admission and increased the frequency of hospitalization. Previously, various levels of adherence in many countries have been observed. In North America, adherence level was reported to be $55 \%$ while $72.9 \%$ was reported in sub-Saharan Africa (Reda and Biadgilign, 2012; Heestermans et al 2016).

In Nigeria, the level of adherence recorded in Kano by Muktar et al 2006 was $49.2 \%$ while in Benin City and Ilorin the levels were 58\% (Erah and Arute, 2008) and 73.3\% (Bello, 2011) respectively. This study examines the level of adherence and pharmaceutical care 
interventions among HIV patients on combined antiretroviral therapy in Nigeria.

\section{EXPERIMENTAL}

\section{Materials and Methods}

The research was conducted in the Infectious Disease Clinic of University of Benin Teaching Hospital (UBTH), Benin City, Edo State, Nigeria. A prospective study was conducted between 15th October, 2012 and 3rd October 2013 following approval by the Ethics and Research Committee of UBTH (Protocol Number: ADM/E22/A/VOL. VII/833). Verbal and written informed consents were obtained from the patients before enrolment.

The case notes of 297 patients among those on cART for 2-8 years who were on first-line antiretroviral drugs (Zidovudine + Lamivudine + Nevirapine; Zidovudine +Lamivudine + Efavirenz; Tenofovir + Emtricitabine + Efavirenz; Tenofovir + Emtricitabine + Nevirapine) and second line combination (Zidovudine + Lamivudine + Lopinavir boosted Ritonavir; Tenofovir + Emtricitabine + Lopinavir boosted Ritonavir) were randomly selected from 10,440 patients.

\section{Pill counting method of adherence measurement}

In this method, the remaining pills brought to the pharmacy by the patient whenever visiting the hospital for a prescription refill was counted and matched against his/her prescription. Adherence level in percentage was determined by dividing actual pills actually consumed over a period with the pills prescribed to have been taken for the period and multiplying by 100 .

\section{Patient-focused intervention}

The patients were followed-up for 9 months with drug counseling at 3 months interval they visited the hospital for prescription refills. All the patients were duly counseled on the beneficial effects and toxicities of cART. Also, the importance of adhering to cART and the possibility of drug resistance and therapeutic failure were emphasized.

\section{Data analysis}

The collected data of the study were analyzed with SAS software program version 9.2.

\section{RESULTS AND DISCUSSION}

All the HIV patients were on at least three cART drugs, of which Zidovudine-Lamivudine-
Nevirapine combination; a first-line regimen was mostly used. Second-line regimens (Zidovudine + Lamivudine + Lopinavir / ritonavir and Tenofovir + Emtricitabine + Lopinavir / Ritonavir) were reserved for patients who defaulted in their treatment and these accounted for 22 (8.5\%) (Table 1). Greater than half of HIV patients had been on cART between a period of 2 and 3 years. The median of the duration on cART was 3.4 years. Only limited patients that were on cART reported minimal side effects, particularly body weakness. No one among the patients was on herbal medicines during the investigation period. The preferred method of medicationtaking behavior among the patients was self or alarm reminder (Table 1). At baseline, the adherence level obtained from pill counting was 85.9\%. Following the patient-focused interventions, the adherence level steadily increased to $97 \%$ (Figure 1). Prior to intervention, adherence to cART drugs recorded among the patients was much higher (85.9\%) than those of earlier studies such as that of (Erah and Arute 2008) where adherence level of 58\% was reported. This variance in adherence level can be explained based on the advancement in the WHO 2014 antiretroviral therapy treatment guideline, free cART drugs and patient-focused interventions provided on medications and disease treatment.

Prior to pharmacist intervention, the HIVinfected patients were mostly adhered to Tenofovir + Emtricitabine + Efavirenz followed by Zidovudine + Lamivudine + Efavirenz. After intervention, there was advancement in adherence to all drug regimes (Table 2). The commonest reasons for inapt adherence to cART medication at baseline were drug fatigue, wrong drug information and religion constraint (Figure 2). Furthermore, no one among the patients was on herbal medicines; therefore, consuming traditional drugs could contribute to inapt drug adherence. Besides, this study validates with the earlier findings (Mini et al 2012) that poor knowledge about patients' disease stage and appropriate therapy was the cogent reason for low level of adherence.

The regression analysis revealed that greater drug adherence was only associated with the duration on cART in HIV-infected patients [OR 2.1; 95\% confidence interval 1.0-1.4, $\mathrm{p}<0.05$ ]. The longer a patient is on cART, the better the adherence level (Table 3). However, adherence was still below the minimum level of $95 \%$ (Lam and Fresco, 2015). 


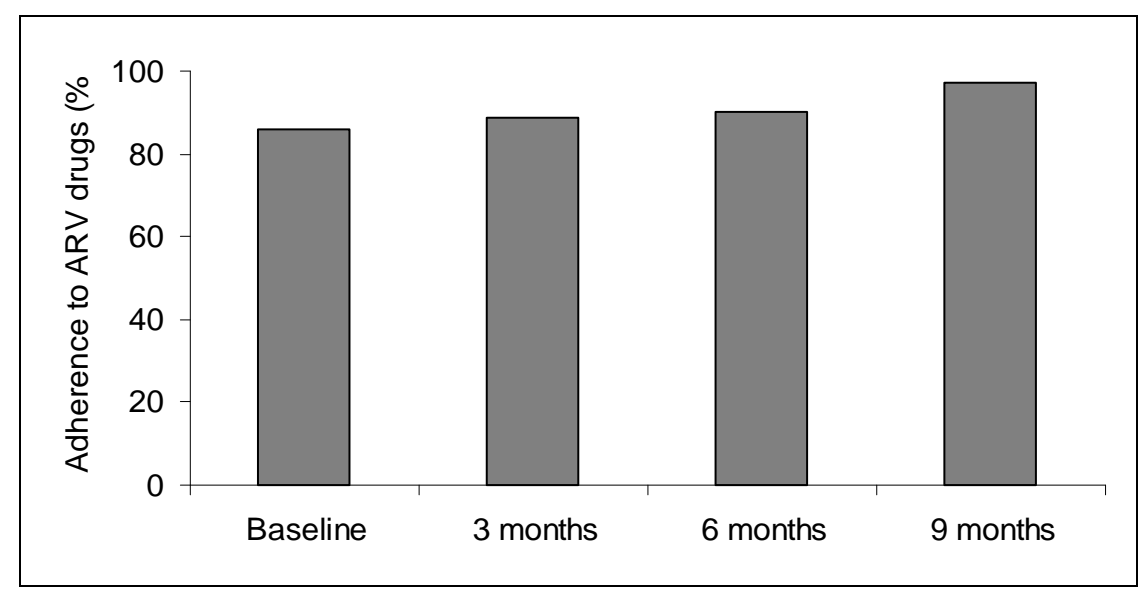

Fig. 1. Adherence to cART by HIV-infected patients following pharmacist's patient intervention

Table 1. Treatment characteristics of HIV-infected patients on cART

\begin{tabular}{|c|c|}
\hline Characteristics & Frequency (\%) \\
\hline \multicolumn{2}{|l|}{ Combined Antiretroviral Therapy (cART) } \\
\hline Zidovudine + Lamivudine + Nevirapine (ZLN) & $211(70.6)$ \\
\hline Zidovudine + Lamivudine + Efavirenz (ZLE) & $20(6.9)$ \\
\hline Zidovudine + Lamivudine + Lopinavir/ritonavir (ZLA) & $13(4.5)$ \\
\hline Tenofovir + Emtricitabine + Efavirenz (TEE) & $25(8.5)$ \\
\hline Tenofovir + Emtricitabine + Nevirapine (TEN) & $16(5.5)$ \\
\hline Tenofovir + Emtricitabine + Lopinavir/ritonavir (TEA) & $12(4.0)$ \\
\hline \multicolumn{2}{|l|}{ Duration on cART (years) } \\
\hline $2-3$ & $156(52.8)$ \\
\hline $4-5$ & $85(28.3)$ \\
\hline $6-8$ & $56(18.9)$ \\
\hline \multicolumn{2}{|l|}{ Antiretroviral Side Effects } \\
\hline Body weakness & $85(28.6)$ \\
\hline Fever & $85(28.6)$ \\
\hline Insomnia & $64(21.4)$ \\
\hline Persistent headache & $32(10.7)$ \\
\hline Infertility & $21(7.1)$ \\
\hline Amenorrhoea & $10(3.6)$ \\
\hline \multicolumn{2}{|l|}{ Prompter of Drug Administration } \\
\hline Use of alarm/self-reminder & $215(72.4)$ \\
\hline Spouse & $40(13.3)$ \\
\hline Family member & $23(7.8)$ \\
\hline Adherence counselor & $12(4.1)$ \\
\hline NTA news & $7(2.4)$ \\
\hline Herbal Medicines & \\
\hline Patients on herbs & $0(0)$ \\
\hline
\end{tabular}

Table 2. Adherence distribution to cART according to drugs used

\begin{tabular}{|c|c|c|}
\hline cART & $\begin{array}{c}\text { Adherent patients } \\
\text { Pre-intervention } \\
\text { n (\%)/total }\end{array}$ & $\begin{array}{c}\text { Adherent patients } \\
\text { Post-intervention } \\
\text { n (\%)/total }\end{array}$ \\
\hline ZLN & $22(59.5) / 211$ & $62(68.1) / 211$ \\
\hline ZLE & $4(10.8) / 21$ & $9(9.9) / 21$ \\
\hline ZLA & $2(5.4) / 13$ & $4(4.4) / 13$ \\
\hline TEE & $5(13.5) / 25$ & $9(9.9) / 25$ \\
\hline TEN & $3(8.1) / 16$ & $4(4.4) / 16$ \\
\hline TEA & $1(2.7) / 11$ & $3(3.3) / 11$ \\
\hline Total & $37 / 297$ & $91 / 297$ \\
\hline
\end{tabular}

Z: Zidovudine, L: Lamivudine, N: Nevirapine, E: Efavirenz, E: Emtricitabine, A: Lopinavir/Ritonavir, T: Tenofovir 


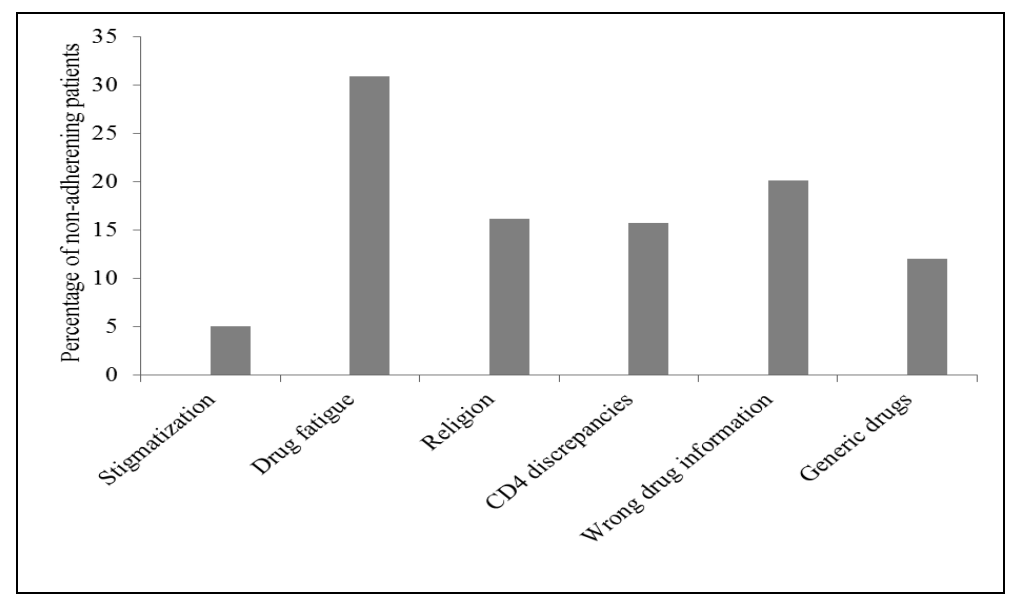

Fig. 2. Reasons for inapt adherence to cART drugs among the patients at baseline

Table 3. Logistic analysis for determinants of better adherence in HIV-infected patients on cART

\begin{tabular}{|c|c|c|}
\hline Factor & OR (95\% CI) & P-value \\
\hline \multicolumn{3}{|l|}{ Age (years) } \\
\hline $20-30$ & $2.416(0.682-8.556)$ & 0.172 \\
\hline $31-40$ & $1.114(0.453-2.738)$ & 0.814 \\
\hline $41-50$ & $1.117(0.459-2.722)$ & 0.807 \\
\hline $50^{+}$ & $1.000(0.192-2.012)$ & 0.158 \\
\hline \multicolumn{3}{|l|}{ Gender } \\
\hline Male & $1.315(0.755-2.288)$ & 0.333 \\
\hline Female & $1.000(0.875-4.134)$ & 0.365 \\
\hline \multicolumn{3}{|l|}{ Marital status } \\
\hline Single & $0.542(0.211-1.394)$ & 0.204 \\
\hline Married/ever married & $1.000(0.515-5.863)$ & 0.511 \\
\hline \multicolumn{3}{|l|}{ Education } \\
\hline Not educated & $1.559(0.414-5.863)$ & 0.511 \\
\hline Primary school & $0.688(0.312-1.515)$ & 0.353 \\
\hline Secondary school & $0.858(0.403-1.826)$ & 0.691 \\
\hline Post-secondary & $1.000(0.111-0.349)$ & 0.223 \\
\hline \multicolumn{3}{|l|}{ Occupation } \\
\hline Unemployed/students & $1.587(0.622-4.051)$ & 0.334 \\
\hline Employed/retired & $1.000(0.691-9.836)$ & 0.157 \\
\hline \multicolumn{3}{|l|}{$\begin{array}{c}\text { cART regimen } \\
\end{array}$} \\
\hline Zidovudine + Lamivudine + Nevirapine & $1.061(0.309-3.644)$ & 0.926 \\
\hline Zidovudine + Lamivudine + Efavirenz & $0.666(0.165-2.684)$ & 0.568 \\
\hline Tenofovir + Emtricitabine + Efavirenz & $0.938(0.186-4.743)$ & 0.939 \\
\hline $\begin{array}{c}\text { Tenofovir }+ \text { Emtricitabine }+ \\
\text { Nevirapine } \\
\end{array}$ & $1.881(0.339-10.428)$ & 0.470 \\
\hline $\begin{array}{l}\text { Tenofovir + Emtricitabine + } \\
\text { Lopinavir/Ritonivir }\end{array}$ & $0.931(0.194-4.469)$ & 0.929 \\
\hline $\begin{array}{l}\text { Zidovudine + Lamivudine + } \\
\text { Lopinavir/Ritonivir }\end{array}$ & $1.000(0.145-4.902)$ & 0.717 \\
\hline Duration on cART & $1.180(1.001-1.390)$ & $0.048^{*}$ \\
\hline
\end{tabular}

*Statistically Significant at P < 0.05, Z: Zidovudine, L: Lamivudine, N: Nevirapine, E: Efavirenz,

E: Emtricitabine, T: Tenofovir, A: Lopinavir/Ritonavir

The improvement in adherence level in the present research following intervention has been reported elsewhere (Mini et al 2012). Adherence to the medication was insignificantly affected by the gender, age, marital status, occupation, educational attainment and type of
cART regimen in this study, similar to in Cross River State and in Sokoto State of Nigeria (Oku et al 2014; Agu et al 2013). In this research, however, duration of therapy with cART was appreciably correlated with better drug adherence (Talam et al 2008). 


\section{CONCLUSION}

Prior to the intervention, the HIV-infected patients mostly adhered to Tenofovir + Emtricitabine + Efavirenz followed by Zidovudine + Lamivudine + Efavirenz. After the intervention, there was an improvement in

\section{REFERENCES}

Adefolalu AO, Nkosi ZZ. The complex nature of adherence in the management of HIV/AIDS as a chronic medical condition. Diseases 2013;1(1):18-35. [DOI: 10.3390/disea ses1010018]

Agu KA, Omonaiye 0, Oqua D, Sani T, Isah MA, Olayemi S, King RC, Wutoh AK. Medication adherence and cluster of differentiation 4 (CD4) cells response in patients receiving antiretroviral therapy. J. AIDS HIV Res. 2013; 5(5):163-9. [DOI: 10.5897/JAHR2013.0244]

Bello SI. HIV/AIDS patients' adherence to antiretroviral therapy in Sobi Specialist Hospital, Ilorin, Nigeria. Glob. J. Med. Res 2011;11(12):17-25.

Erah PO, Arute JE. Adherence of HIV/AIDS patients to antiretrovitral therapy in a tertiary health facility in Benin City. Afr. J. Pharm. Pharmacol 2008;2(7):145-52.

Heestermans T, Browne JL, Aitken SC, Vervoort SC, Klipstein-Grobusch K. Determinants of adherence to antiretroviral therapy among HIV-positive adults in subSaharan Africa: A systematic review. BMJ Glob. Health 2016;1(4):e000125. [DOI: 10.1136/bmjgh-2016-000125].

Hornschuh S, Dietrich JJ, Tshabalala C, Laher F. Antiretroviral treatment adherence: Knowledge and experiences among adolescents and young adults in Soweto, South Africa. AIDS Res. Treat. 2017;(2017): 5192516 (1-6). [DOI: 10.1155/2017/5192516]

Lam WY, Fresco P. Medication adherence measures: An overview. BioMed Res. Int. 2015;(2015):217047 (1-12).

Mini KV, Adepu R, Parthasarathi G, Mothi SN, Swamy VT. Impact of pharmacist provided education on medication adherence to all the drugs regimens utilized. In treating HIV-infected patients on combined antiretroviral therapy, application of the pharmaceutical interventions and continual monitoring are essential in improving adherence and promoting survival.

adherence behaviour in HIV/AIDS patients treated at a non-government secondary care hospital in India. J. AIDS HIV Res. 2012;4(4):94-9. [DOI: 10.5897/JAHR11.027]

National Consolidated Guidelines. Guidelines for the prevention of mother-to-child transmission of HIV (PMTCT) and the management of HIV in children, adolescents and adults. National Department of Health, Pretoria, South Africa, April 2015.

Oku AO, Owoaje ET, Oku 00, Monjok E. Prevalence and determinants of adherence to highly active antiretroviral therapy amongst people living with HIV/AIDS in a rural setting in south-south Nigeria. Afr. J. Reprod. Health 2014;18(1):133-43.

Reda AA, Biadgilign S. Determinants of adherence to antiretroviral therapy among HIV-infected patients in Africa. AIDS Res. Treat. 2012;(2012):574656 (1-8). [DOI: 10.1155/2012/574656]

SAS. The Statistical Application Software (SAS) Statistics System for Windows Release Version S9.2. SAS Institute, Inc. Cary, NC, USA. 2012.

Talam NC, Gatongi P, Rotich J, Kimaiyo S. Factors affecting antiretroviral drug adherence among HIV/AIDS adult patients attending HIV/AIDS Clinic at MOI Teaching and Referral Hospital, Eldoret, Kenya. East Afr. J. Public Health 2008;5(2):74-8.

WHO. Consolidated guidelines on the use of antiretroviral drugs for treating and preventing HIV infection: Recommendations for a public health approach. Geneva: World Health Organization, 2015. 